\title{
Modelling of Maximum Annual Flood for Regional Watersheds Using Markov Model
}

\author{
Benjamin Nnamdi Ekwueme ${ }^{1}$, Andy Obinna Ibeje ${ }^{2 *}$, Anthony Ekeleme ${ }^{3}$ \\ ${ }^{1}$ Department of Civil Engineering, Faculty of Engineering, University of Nigeria Nsukka Enugu State, Nigeria \\ ${ }^{2}$ Department of Civil Engineering, Faculty of Engineering, Imo State University, Owerri, Nigeria \\ ${ }^{3}$ Department of Civil Engineering, Faculty of Engineering, Abia State University, Uturu, Nigeria
}

DOI: $10.36348 /$ sjce.2021.v05i02.002

| Received: 07.02.2021 | Accepted: 22.02.2021 | Published: 08.03.2021

*Corresponding author: Andy Obinna Ibeje

\section{Abstract}

A study was undertaken to develop and apply the first-order Markov model in generating the synthetic stream flow for Adada, Ivo, Otamiri, Imo and Ajali rivers located in South East Nigeria. The best-fit probability distributions for the maximum annual stream flows were lognormal, Weibull, normal and lognormal for Adada, Ajali, Ivo, Otamiri and Imo (Umuokpara) rivers respectively were used in simulating the associated random deviates. The stream flow data for 10 years (1980 to 1989) were used to develop the model and to predict the stream flow. The model performance was evaluated with the aid of the coefficient of determination (R2). The results indicated a satisfactory performance as evidenced by R2 values of $51.69 \%, 31.3 \%, 21.4 \%, 33 \%$ and $21 \%$ for Adada, Ajali, Ivo, Otamiri and Imo rivers respectively. The developed models were used to generate 50-year synthetic stream flows of these rivers. The study showed that the annual Markov models have proved to be a powerful tool to extend 10-year record of maximum annual runoffs.

Keywords: Markov Model, Synthetic Stream Flow, South East Nigeria.

Copyright ( $) 2021$ The Author(s): This is an open-access article distributed under the terms of the Creative Commons Attribution 4.0 International License (CC BY-NC 4.0) which permits unrestricted use, distribution, and reproduction in any medium for non-commercial use provided the original author and source are credited.

\section{INTRODUCTION}

There has been a severe increase in water scarcity in several regions around the globe owing to anthropogenic activities and climate change [1-3]. One of the major problems being faced by water resources engineers is the issue of determining the most applicable type of extreme value model, approximating the variables in the distribution and obtaining the required probability for flood distribution [4]. Real-time approach to flood forecasting together with the construction of gigantic hydraulic structures can aid in mitigating drought and flood hazards, as well as minimizing their associated losses [5]. However, owing to the extreme probability of their events, the danger arising from these natural disasters cannot be totally avoided, and thereby constituting much challenge to the water engineers in trying to estimate the frequency of their occurrences for a particular region [6]. In recent years, various studies have focused on the generation of synthetic stream flows across the world. To evaluate the anticipated water resources performance, simulation studies are usually performed using stochastic models for annual stream flow [7]. The generated synthetic stream flows are of equivalent significance as the historic stream flow in studying diverse practicable alternatives in the planning, design as well as in the operation of water resources schemes [8]. A reliable generation of synthetic stream flow is, therefore, of importance for territorial water resources implementations such as water transfer, maximum water resources distribution and reservoir management programmes [9].

Basically, the two major approaches in hydrological modelling are stochastic and deterministic modeling. The deterministic model takes into account the effect of biological, chemical and physical processes which take place within the hydrological system. The stochastic model on the other hand, generates the randomness existing between the hydrological outputs and inputs. A limited number of parameters exhibit a unique relationship involving the experimental curves or the functional descriptions for representing a hydrological system within the system [10]. This type of technique is applicable in conceptual- based models like the soil moisture computational model [11].

The regular hydrological processes can be stochastic and deterministic or only stochastic models. 
Deterministic models can be used in the appreciable description of the actuality of a hydrological system particularly in cases when the intensity of uncertainty is appreciably small. Owing to an increase in the awareness on the varieties of sources for uncertainty in basically, all facets of environmental modelling, developing modelling approaches which take into account the stochastic nature of environmental processes is imperative [12].

The time series models are the most commonly used, and they are used for simulation or hydrological forecasting [11] and they include the Nearest Neighbour Method, the ARMA-Markov model and the Autoregressive Moving Average Model (ARMA) [13]. In a related study [14], suggested a non-parametric approach for the generation of long span of stream flow prediction. This approach is based mainly on daily use of non-parametric-based regression analysis and stream flow data for relating the covariate to the forecast variables.

The theory and application of Markov process are well documented in literature. Markov chains have been used for stream flow generation in long, medium and short-range hydrological prediction. The application of Markov chains technique in run-off rainfall modeling has been in use for ages. A first order Markov chain was proposed by Gabriel in 1957 for simulating the event of dry and wet seasons [11]. In another research [15], adopted a Markov-based mixture model in generating the annual synthetic stream flows. The model is made up of a two-state-based Markov chain in which the states considered were the normal together with the low stream flows, whereas the values of the stream flows in each of the states were generated with the aid of two normal distributions. The model was found important in the sizing of the reservoir owing to its capacity in generating consistent stochastically synthetic stream flow series for dry seasons. Jackson, B. B [16] equally suggested a continuous time Markov chain death-birth process with the aid of discrete stream flow levels as state, in the modelling of the phenomenological monitoring showing that low values of stream flow are more persistent than those of high ones. The model was successful in the generation of annual stream flows used in the optimization of the reservoir emission. Haan, C. T et al., [17] gave a Markov-based chain model of first order which was tested using seven rainfall stations with the aid of $7 \times 7$ transition matrices. The geometric progression was adopted in the determination of the class boundaries across the various states present in the Markov chain. A comparison was done between the actual and the simulated rainfall in different scenarios, and it was found out that the model exhibited satisfactory performance. Yakowitz, S. T [18] presented a nonparametric based Markov model for use in short-terrn forecasting. The model entails the inference on the distribution of conditional probability for the subsequent stream flow which is assigned to its current value. In comparison with the ARMA modelling approach, the non-parametric based model showed a better performance. Yakowitz, S. T [18] described the $\mathrm{N}$-th order class of Markov chain models as a daily stream flow model, and he proposed statistical based approaches for inference within the class. $\mathrm{He}$ highlighted the characteristics of the $\mathrm{N}$-th order Markov chain models as being unique amidst the nonparametric stream flow models. With the use of this device, ignoring traditional but unreliable assumptions such as prior assumptions on time distribution between extreme occurrences, recessions and gamma distribution of flows is possible. Katz, R. W [19] in his study, carried out an analysis on the approach suggested by Tong in 1975, in estimating the order of Markov chain using Bayesian and Akaike's Information Criteria. He inferred that models of higher magnitude than the first-order chains should not be regarded. Yakowitz, S. $\mathrm{T}$ [20] adopted the non-parametric approach in the modelling of data from stream flow on the issue of flood alerts. He described a non-parametric inference technique which approaches the optimum decision function in the case of flood warning, when there is an increase in the span of the historical record for any immobile Markov procedure in accordance with [20]. In another study [14], obtained a non-parametric technique for generating distributive forecasts involving long-span stream flow variables with the aid of conceptual hydrological models.

Although, some researches have been carried out on the prediction of annual rainfall Markov model, to the best of our knowledge no study has been reported on modelling of maximum annual flood for South East, Nigeria using Markov model. Given 10-year data of maximum annual runoffs, this study is focused on the generation of 30-year synthetic data of five rivers drawn from each of the five states of South East, Nigeria using Markov model.

\section{METHOD \\ Study Area}

The south-eastern part of Nigeria is an area which covers about $76,358 \mathrm{~km}^{2}$ south of the Benue valley and east of the lower Niger. In terms of geopolitical zones, the region consists of five states out of 36 states in Nigeria, and they include Abia, Anambra, Ebonyi, Enugu and Imo states. The region is situated between longitudes $7^{0} \mathrm{E}$ and $9{ }^{0} \mathrm{E}$ and latitudes $4^{0} \mathrm{~N}$ and $7{ }^{0} \mathrm{~N}$. In terms of relief, the land surface of eastern part of Nigeria can be classified as plains, highlands and the lowlands [21]. These are the plains and Climate-wise, eastern Nigeria is characterized by seasonal distribution of rainfall which depends on the interaction of the Equatorial Easterlies, Tropical Maritime air mass and Tropical Continental air mass. The rainfall pattern is characterized by long rainy season as well as short dry season, and it is controlled by the movement involving inter-tropical convergence. The long rainy season starts 
from April to July, while the short dry season occurs in August, and it is followed by a short rainy season which occurs between September to October [21]. The map of the study area is shown in Fig-1 while the monthly discharge records that were used cover over 10 years for the selected Rivers Adada in Enugu, Otamiri in Owerri, Ivo in Ebonyi and Imo (umuokpara) in Umuahia (Table-1).

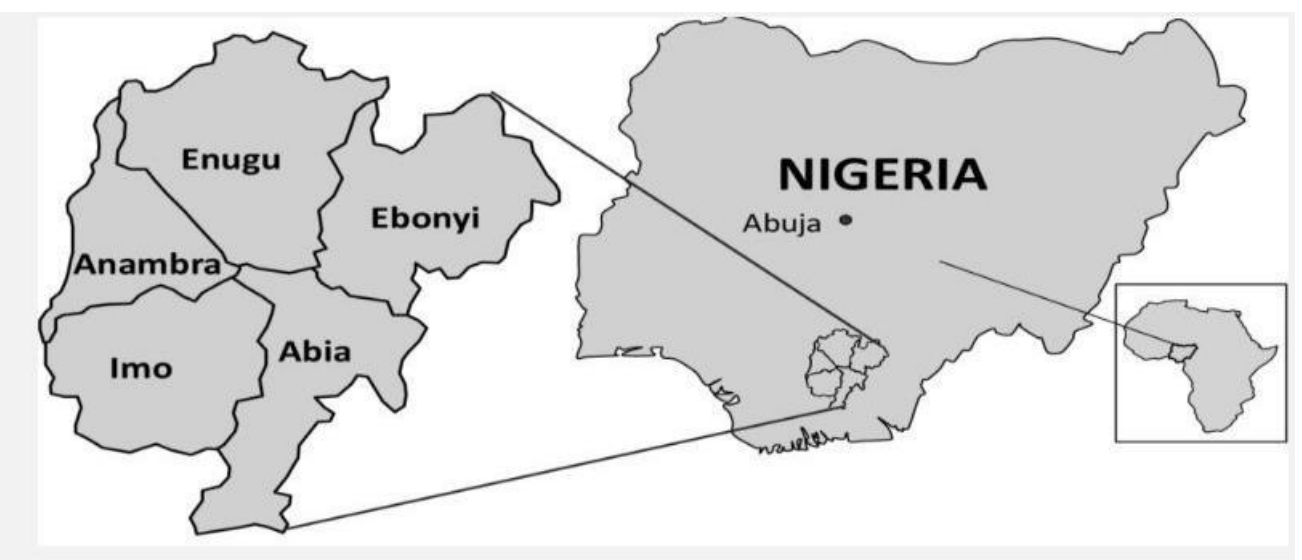

Fig-1: Major Towns of South-eastern Nigeria

Source: Ofomata, G.E.K. [21]

Table-1: Geographical locations for the Rivers

\begin{tabular}{|l|l|l|l|l|l|l|l|}
\hline STATE & RIVER & STATION & LAT. & LONG. & $\begin{array}{l}\text { CATCHMENT } \\
\text { AREA }\left(\mathbf{K m}^{\mathbf{2}}\right)\end{array}$ & $\begin{array}{l}\text { ZERO LEVEL } \\
\text { OF GAUGE (m) }\end{array}$ & $\begin{array}{l}\text { G B M } \\
\text { LCAL (m) }\end{array}$ \\
\hline IMO & Otamiri & Nekede & $05^{\circ} 26^{\prime}$ & $07^{\circ} 02^{\prime} \mathrm{E}$ & 100 & 97.71 & 100 \\
\hline Abia & Abia & Umuopara & $05^{\circ} 33^{\prime} \mathrm{N}$ & $07^{\circ} 25^{\prime} \mathrm{E}$ & 1450 & 86.50 & 100 \\
\hline Anambra & Adada & Umulokpa & $06^{\circ} 38^{\prime} \mathrm{N}$ & $07^{\circ} 11^{\prime} \mathrm{E}$ & 890 & NA & NA \\
\hline Enugu & Ajali & $\begin{array}{l}\text { Aguobu- } \\
\text { umumba }\end{array}$ & $07^{\circ} 19^{\prime} \mathrm{N}$ & $07^{\circ} 13^{\prime} \mathrm{E}$ & 900 & NA & NA \\
\hline Ebonyi & Ivo & Imezi-Olo & $06^{\circ} 28^{\prime} \mathrm{N}$ & $06^{\circ} 11^{\prime} \mathrm{E}$ & 125 & NA & NA \\
\hline
\end{tabular}

Source: Anambra-Imo River Basin Authority, Owerri

$\mathrm{NA}=$ Not applicable.

The discharge data were obtained from the Anambra-Imo River Basin Authorities. The maximum monthly runoffs of the selected basins were collated from the available discharge records to form a time series of maximum annual runoff for the selected catchment of Rivers Adada in Enugu, Otamiri in Owerri, Ivo in Ebonyi and Imo (umuokpara) in Umuahia (Table-2).

\section{Identification and Distribution of Annual Runoff}

The historical ten (10)-year stream flow data were extended using the Markov Model for the five rivers under study by initially ascertaining the probability distribution of the random deviates associated with the annual runoff data of the rivers under study. Initially, Log normal, Normal, Generalized Extreme Value, Log Pearson, Gumbel, Log-Pearson type 3 and Pearson type 3 statistical distributions were fitted to the maximum monthly runoff for 10 years of data (1980-1989) for the stream gauging stations in each of the five states of southeastern Nigeria.
To ascertain the probability distribution of the random deviates associated with the annual runoff data the rivers under study, the best fitting distribution for the annual discharge was obtained using the AndersonDarling test as expressed in Equations 1 and 2. The probability distribution of the annual runoff was calculated using the Minitab software application. The distribution having the highest value of $p$ was accepted as the probability distribution of the random variable. This study used the Anderson-Darling (A-D) test to confirm the statistical hypothesis showing whether a particular probability distribution gives an adequate fit to the measured annual maximum flood series data and can be approved as the best fit distribution. The goodness of fit tests were performed to measure the distance existing between the distribution and the data being tested as well as to compare the distance obtained with some threshold value. The distance obtained is known as the test statistic, while the threshold value is known as the critical value. 
Table-2: Maximum Annual Discharge of Selected Rivers in south east Nigeria

\begin{tabular}{|l|l|l|l|l|l|}
\hline \multirow{2}{*}{ Year } & \multicolumn{2}{l}{ Maximum Annual Discharge $\left.\mathbf{( m}^{\mathbf{3}} / \mathbf{s}\right)$} \\
\cline { 2 - 6 } & River Ivo & River Ajali & River Imo (umuokpara) & River Otamiri & River Adada \\
\hline $1978 / 79$ & 0.00 & - & 270.00 & 12.10 & - \\
\hline $1979 / 80$ & 11.33 & 12.15 & 158.40 & 12.90 & 50.28 \\
\hline $1980 / 81$ & - & 12.65 & - & 10.55 & 42.51 \\
\hline $1981 / 82$ & - & 12.24 & - & 11.48 & 46.95 \\
\hline $1982 / 83$ & 11.33 & 12.61 & 158.37 & 7.20 & 46.71 \\
\hline $1983 / 84$ & 11.18 & 12.55 & 156.04 & 10.70 & 57.13 \\
\hline $1984 / 85$ & 10.91 & 12.61 & 126.20 & 9.38 & 50.53 \\
\hline $1985 / 86$ & 10.91 & 12.55 & 194.40 & 11.78 & 45.67 \\
\hline $1986 / 87$ & 10.91 & 11.8 & 115.00 & 13.54 & 47.86 \\
\hline $1987 / 88$ & 10.90 & 12.27 & 223.20 & - & 47.99 \\
\hline $1988 / 89$ & 10.91 & 12.44 & 42.85 & - & 50.15 \\
\hline
\end{tabular}

Source: Anambra-Imo River Basin Authority, Owerri

If the value of test statistic is less than the critical value, then the fit is regarded as a good one. The test was performed at $5 \%$ significant levels. The symbol $\mathrm{X}$ signifies the random variable for the annual maximum flows, while $\mathrm{n}$ denotes the sample size. To compare the fit of an observed cumulative distribution function with an expected cumulative distribution function, the Anderson-Darling procedure was used. The Anderson-Darling test statistic (AD) is given in Equation 1.

$$
A D=-n-\frac{1}{n} \sum_{i=1}^{n}(2 i-1)\left[\operatorname{InF}\left(x_{i}\right)-\operatorname{In}(1-X n-i-1)\right]
$$

Where $F(X)$ and $i$ are the cumulative distribution function in the specified distribution and the ith sample with the data arranged in ascending order

$$
\mathrm{AD}^{*}=\mathrm{AD}\left(1+\frac{0.75}{\mathrm{n}}+\frac{2.25}{\mathrm{n}^{2}}\right)
$$

\section{Synthetic Generation of Annual Discharge}

Markov model was used in this study to extend the length of the historical data obtained from the stream flow. The sample parameters of the annual flow respectively. After obtaining $\mathrm{AD}$, the value was adjusted for small sample sizes using Equation 2.

The arithmetic mean $\mu$ of the historical 10 years data of runoff was obtained using Equation 3 .

$$
\mu=\sum_{t=1}^{n} \frac{X_{t}}{N}
$$

Serial covariance zero, $C_{o}$, was used to obtain the variance as shown in Equation 4.

$$
\mathrm{C}_{\mathrm{O}}=\sum_{\mathrm{t}=1}^{\mathrm{n}} \frac{\left(\mathrm{X}_{\mathrm{t}}-\mu\right)^{2}}{\mathrm{~N}}
$$

The lag-one serial correlation coefficient was used in describing the strength of the relationship between a value in the sequence and that preceding it by one-time interval; i.e lag-one. The data is denoted by distribution such as the mean, variance and lag-one serial correlation coefficient were initially estimated using the following relations:

$$
C i=\sum_{t=1}^{n} \frac{\left(x_{t}-\mu\right)\left(x_{t-1}-\mu\right)}{N}
$$

$\mathrm{r}_{1}$ where time, $\mathrm{t}=1,2,3 \ldots 10$ years. To obtain lag-one serial correlation coefficient $r_{1}$, the following steps were followed: the serial covariance one, $\mathrm{C}_{1}$ was first evaluated using Equation 5.

The lag-one serial correlation coefficient (r) was calculated using Equation 6.

$$
\mathrm{r}_{1}=\mathrm{Ci} / \mathrm{Co}
$$

For generating annual flows Q, the first-order Markov model is given in Equation7.

$$
\mathrm{Q}=\overline{\mathrm{Q}}+\mathrm{r}_{\mathrm{i}}\left(\mathrm{Q}_{\mathrm{i}}-\overline{\mathrm{Q}}\right)+\mathrm{z}_{\mathrm{i}} \sigma \sqrt{1-\mathrm{r}_{\mathrm{i}}^{2}}
$$


Where $\sigma=$ standard deviation of $\mathrm{Q}, \mathrm{Z}_{\mathrm{i}}$ is the random deviate whose distribution was established. $\bar{Q}=$ mean of $\mathrm{Q}, \mathrm{i}=1$ year to $\mathrm{n}$ year (flows in series), $\mathrm{r}_{\mathrm{i}}=1$ lag autocorrelation coefficient. Markov The model assumed generally that the $\mathrm{z}_{\mathrm{i}}$ in the generation equation are distributed independently with constant variance and mean zero and as the annual runoff data. The model also assumed that the whole impact the previous flow had on the current one is reflected in the value of the previous flow. These computations were done using Microsoft Excel software application.

\section{RESULTS \\ Probability Distributions of Maximum Annual Runoff}

The distribution having the highest value of $p$ was accepted as the probability distribution of the random deviates as shown in bold font in Table- 3 for Rivers Adada, Ajali, Ivo, Otamiri and Imo (Umuokpara).

Table-3: Results of Anderson-Darling Test for Best Fitting Distribution for Annual Runoff

\begin{tabular}{|l|l|l|l|}
\hline \multicolumn{4}{|c|}{ Adada River } \\
\hline Distribution & AD & P & LRT P \\
\hline Normal & 0.408 & 0.279 & \\
\hline Lognormal & $\mathbf{0 . 3 5 4}$ & $\mathbf{0 . 3 8 5}$ & \\
\hline 3-Parameter Lognormal & 0.308 & $*$ & 0.534 \\
\hline Exponential & 3.987 & $<0.003$ & \\
\hline 2-Parameter Exponential & 1.140 & 0.023 & 0.000 \\
\hline Weibull & 0.673 & 0.067 & \\
\hline 3-Parameter Weibull & 0.368 & 0.446 & 0.065 \\
\hline Smallest Extreme Value & 0.781 & 0.035 & \\
\hline Largest Extreme Value & 0.324 & $>0.250$ & \\
\hline Gamma & 0.365 & $>0.250$ & \\
\hline 3-Parameter Gamma & 0.770 & $*$ & 1.000 \\
\hline Logistic & 0.300 & $>0.250$ & \\
\hline Loglogistic & 0.273 & $>0.250$ & \\
\hline 3-Parameter Loglogistic & 0.250 & $*$ & 0.607 \\
\hline
\end{tabular}

\begin{tabular}{|l|l|l|l|}
\hline \multicolumn{4}{|c|}{ Ajali River } \\
\hline Distribution & AD & P & LRT P \\
\hline Normal & 0.556 & 0.112 & \\
\hline Lognormal & 0.570 & 0.103 & \\
\hline 3-Parameter Lognormal & 0.584 & $*$ & 0.641 \\
\hline Exponential & 4.413 & $<0.003$ & \\
\hline 2-Parameter Exponential & 1.785 & $<0.010$ & 0.000 \\
\hline Weibull & $\mathbf{0 . 4 9 2}$ & $\mathbf{0 . 2 0 5}$ & \\
\hline 3-Parameter Weibull & 0.485 & 0.133 & 0.746 \\
\hline Smallest Extreme Value & 0.485 & 0.211 & \\
\hline Largest Extreme Value & 0.786 & 0.034 & \\
\hline Gamma & 0.592 & 0.136 & \\
\hline 3-Parameter Gamma & 5.809 & $*$ & 1.000 \\
\hline Logistic & 0.516 & 0.138 & \\
\hline Loglogistic & 0.523 & 0.129 & \\
\hline 3-Parameter Loglogistic & 0.516 & $*$ & 0.694 \\
\hline
\end{tabular}

Ivo River
\begin{tabular}{|l|l|l|l|}
\hline Distribution & AD & P & LRT P \\
\hline Normal & 1.137 & $<0.005$ & \\
\hline Lognormal & 1.137 & $<0.005$ & \\
\hline 3-Parameter Lognormal & 1.034 & $*$ & 0.000 \\
\hline Exponential & 3.565 & $<0.003$ & \\
\hline 2-Parameter Exponential & 1.961 & $<0.010$ & 0.000 \\
\hline Weibull & $\mathbf{1 . 1 4 6}$ & $<\mathbf{0 . 0 1 0}$ & \\
\hline 3-Parameter Weibull & 1.061 & 0.009 & 0.000 \\
\hline Smallest Extreme Value & 1.146 & $<0.010$ & \\
\hline Largest Extreme Value & 1.438 & $<0.010$ & \\
\hline Gamma & 1.256 & $<0.005$ & \\
\hline 3-Parameter Gamma & 0.949 & $*$ & 0.000 \\
\hline Logistic & 1.163 & $<0.005$ & \\
\hline Loglogistic & 1.164 & $<0.005$ & \\
\hline 3-Parameter Loglogistic & 0.948 & $*$ & 0.000 \\
\hline
\end{tabular}

Otamiri River
\begin{tabular}{|l|l|l|l|}
\hline Distribution & AD & P & LRT P \\
\hline Normal & $\mathbf{0 . 1 6 7}$ & $\mathbf{0 . 9 1 0}$ & \\
\hline Lognormal & 0.311 & 0.495 & \\
\hline 3-Parameter Lognormal & 0.170 & $*$ & 0.252 \\
\hline Exponential & 3.146 & $<0.003$ & \\
\hline 2-Parameter Exponential & 1.467 & $<0.010$ & 0.000 \\
\hline Weibull & 0.129 & $>0.250$ & \\
\hline 3-Parameter Weibull & 0.127 & $>0.500$ & 0.938 \\
\hline Smallest Extreme Value & 0.143 & $>0.250$ & \\
\hline Largest Extreme Value & 0.426 & $>0.250$ & \\
\hline Gamma & 0.254 & $>0.250$ & \\
\hline 3-Parameter Gamma & 3.229 & $*$ & 1.000 \\
\hline Logistic & 0.135 & $>0.250$ & \\
\hline Loglogistic & 0.212 & $>0.250$ & \\
\hline 3-Parameter Loglogistic & 0.135 & $*$ & 0.355 \\
\hline
\end{tabular}

\begin{tabular}{|l|l|l|} 
Imo (Umuokpara) River \\
\hline Distribution & AD & P \\
\hline Normal & $\mathbf{0 . 3 1 7}$ & $\mathbf{0 . 4 8 6}$ \\
\hline 3-Parameter Lognormal & 0.656 & $*$ \\
\hline 2-Parameter Exponential & 0.970 & 0.047 \\
\hline 3-Parameter Weibull & 0.316 & 0.480 \\
\hline Smallest Extreme Value & 0.261 & $>0.250$ \\
\hline Largest Extreme Value & 0.548 & 0.151 \\
\hline 3-Parameter Gamma & 0.635 & $*$ \\
\hline Logistic & 0.327 & $>0.250$ \\
\hline 3-Parameter Loglogistic & 0.391 & $*$ \\
\hline
\end{tabular}


Table-4 shows the random variables associated with Rivers Adada, Ajali, Ivo, Otamiri and Imo (Umuokpara). The random deviates associated with River Adada had a lognormal distribution with the highest $\mathrm{p}$ value of 0.385 . The random deviates associated with River Ajali had a Weibull distribution with the highest $\mathrm{p}$ value of 0.205 . The random deviates associated with River Ivo had a Weibull distribution with the highest $\mathrm{p}$ value of 0.010 . The random deviates associated with River Otamiri had a normal distribution with the highest $\mathrm{p}$ value of 0.910 . The random deviates associated with River Imo (Umuokpara) had a lognormal distribution with the highest $\mathrm{p}$ value of 0.486 .

\section{Model Formulation}

To obtain the equation for generating runoff data beyond the available 10-year data, the mean discharge, $\mu$, correlation coefficient, $r_{1}$ and standard deviation, $\sigma$ respectively as given in Tab. 4 were substituted in Equation 7 to yield the annual Markov model for forecasting of annual discharge in Rivers Otamiri, Imo, Adada, Ajali and Ivo as shown in Table5.

Table-4: Parameters of Annual Discharge for Substituting into Annual Markov Model

\begin{tabular}{|l|l|l|l|l|l|l|l|}
\hline RIVER & STATION & Mean & $\begin{array}{l}\text { St. } \\
\text { Deviation }\end{array}$ & $\begin{array}{l}\text { 1-Lag Autocorrelation } \\
\left(\mathbf{r}_{\mathbf{1}}\right)\end{array}$ & $\begin{array}{l}\text { Probability } \\
\text { Distribution }\end{array}$ & Skewness & Kurtosis \\
\hline Adada & Umulokpa & 48.5771 & 3.86757 & -0.006134 & Lognormal & 0.918875 & 2.32332 \\
\hline Ajali & $\begin{array}{l}\text { Aguobu- } \\
\text { umumba }\end{array}$ & 12.3867 & 0.271846 & -0.086016 & Weibull & -1.21317 & 1.1451 \\
\hline Ivo & Imezi-Olo & 11.0486 & 0.197558 & 0.645272 & Weibull & 0.847137 & -1.51071 \\
\hline Otamiri & Nekede & 11.4236 & 2.12483 & 0.263082 & Normal & -0.576458 & 0.62177 \\
\hline Imo & Umuopara & 131.315 & 87.372 & 0.045242 & Normal & -0.270547 & -0.660512 \\
\hline
\end{tabular}

\section{Model Calibration}

The computation of Markov Model for predicting discharge of Adada River is

$$
\begin{gathered}
\mathrm{Q}=48.5771+(-0.006134) \mathrm{Q}_{\mathrm{i}-1}-(-0.006134) 48.5771+\mathrm{z}_{\mathrm{i}}\left[(3.86757)\left(\sqrt{1-(-0.006134)^{2}}\right)\right] \\
\mathrm{Q}=48.8750719314-0.006134 \mathrm{Q}_{\mathrm{i}-1}+3.86749723881 \mathrm{z}_{\mathrm{i}}
\end{gathered}
$$

The computation of Markov Model for predicting discharge of Ajali River:

$$
\begin{gathered}
\mathrm{Q}=12.3867+(-0.086016) \mathrm{Q}_{\mathrm{i}-1}-(-0.086016) 12.3867+\mathrm{z}_{\mathrm{i}}\left[(0.271846)\left(\sqrt{1-(-0.086016)^{2}}\right)\right] \\
\mathrm{Q}=13.45215438-0.086016 \mathrm{Q}_{\mathrm{i}-1}+0.27084 \mathrm{z}_{\mathrm{i}}
\end{gathered}
$$

The computation of Markov Model for predicting discharge of Ivo River

$$
\begin{gathered}
\mathrm{Q}=11.0486+(0.645272) \mathrm{Q}_{\mathrm{i}-1}-(0.645272) 11.0486+\mathrm{z}_{\mathrm{i}}\left[(0.197558)\left(\sqrt{1-(0.645272)^{2}}\right)\right] \\
\mathrm{Q}=3.9192477808+0.645272 \mathrm{Q}_{\mathrm{i}-1}+0.150925 \mathrm{z}_{\mathrm{i}}
\end{gathered}
$$

The computation of Markov Model for predicting discharge of Otamiri River

$$
\begin{gathered}
Q=11.4236+(0.263082) Q_{i-1}-(0.263082) 11.4236+z_{i}\left[(2.12483)\left(\sqrt{1-(0.263082)^{2}}\right)\right] \\
Q=8.41825664648+0.263082 Q_{i-1}+2.0499796 z_{i}
\end{gathered}
$$

The computation of Markov Model for predicting discharge of Imo (Umuopara) River

$$
\begin{gathered}
\mathrm{Q}=131.315+(0.045242) \mathrm{Q}_{\mathrm{i}-1}-(0.045242) 131.315+\mathrm{z}_{\mathrm{i}}\left[(87.372)\left(\sqrt{1-(0.045242)^{2}}\right)\right] \\
\mathrm{Q}=125.3740404677+0.045242 \mathrm{Q}_{\mathrm{i}-1}+87.282536 \mathrm{z}_{\mathrm{i}}
\end{gathered}
$$

Table-5: Annual Markov Model for Forecasting of Maximum Annual Discharge

\begin{tabular}{|l|c|l|}
\hline Rivers & Annual Markov & $\mathbf{R}^{2}(\boldsymbol{\%})$ \\
\hline Adada river & $\mathrm{Q}=48.8750719314-0.006134 \mathrm{Q}_{\mathrm{i}-1}+3.86749723881 \mathrm{z}_{\mathrm{i}}$ & 51.69 \\
\hline Ajali river & $\mathrm{Q}=13.45215438-0.086016 \mathrm{Q}_{\mathrm{i}-1}+0.27084 \mathrm{z}_{\mathrm{i}}$ & 31.3 \\
\hline Ivo River & $\mathrm{Q}=3.9192477808+0.645272 \mathrm{Q}_{\mathrm{i}-1}+0.150925 \mathrm{z}_{\mathrm{i}}$ & 21.38 \\
\hline Otamiri river & $\mathrm{Q}=8.41825664648+0.263082 \mathrm{Q}_{\mathrm{i}-1}+2.0499796 \mathrm{z}_{\mathrm{i}}$ & 32.97 \\
\hline Imo river & $\mathrm{Q}=125.3740404677+0.045242 \mathrm{Q}_{\mathrm{i}-1}+87.282536 \mathrm{z}_{\mathrm{i}}$ & 21.01 \\
\hline
\end{tabular}




\section{Simulation of Maximum Annual Runoff}

Table-6: Computations for Simulating Maximum Annual Runoff in Adada River

\begin{tabular}{|l|l|l|}
\hline YEAR & $\begin{array}{l}\text { Random Deviates, } \mathbf{z}_{\mathrm{i}}= \\
\text { Inverse lognormal } \\
\text { distribution of random } \\
\text { number = LOGNORM.INV } \\
(\text { RAND, 1,1) (in Excel) }\end{array}$ & $\mathrm{Q}=48.8750719314-0.006134 \mathrm{Q}_{\mathrm{i}-1}+3.86749723881 \mathrm{z}_{\mathrm{i}}$ \\
\hline 1980 & 0.777501 & $\mathrm{Q}_{2}=48.8750719314-0.006134 * 0+3.86749723881 \mathrm{z}_{\mathrm{i}}=50.27546$ \\
\hline 1981 & 3.645211 & $48.8750719314-0.006134 * 50.27546+3.86749723881 \mathrm{z}_{\mathrm{i}}=42.51$ \\
\hline 1982 & 12.9971 & $48.8750719314-0.006134 * 42.51+3.86749723881 \mathrm{z}_{\mathrm{i}}=46.95$ \\
\hline 1983 & 4.163395 & $48.8750719314-0.006134 * 46.95+3.86749723881 \mathrm{z}_{\mathrm{i}}=46.70538$ \\
\hline 1984 & 3.489922 & $48.8750719314-0.006134 * 46.70538+3.86749723881 \mathrm{z}_{\mathrm{i}}=57.13145$ \\
\hline 1985 & 2.783882 & $48.8750719314-0.006134 * 57.13145+3.86749723881 \mathrm{z}_{\mathrm{i}}=50.52656$ \\
\hline 1986 & 1.824315 & $48.8750719314-0.006134 * 50.52656+3.86749723881 \mathrm{z}_{\mathrm{i}}=45.6654$ \\
\hline 1987 & 8.616544 & $48.8750719314-0.006134 * 45.6654+3.86749723881 \mathrm{z}_{\mathrm{i}}=47.86443$ \\
\hline 1988 & 0.629635 & $48.8750719314-0.006134 * 45.6654+3.86749723881 \mathrm{z}_{\mathrm{i}}=47.99252$ \\
\hline 1989 & 2.071504 & $48.8750719314-0.006134 * 47.99252+3.86749723881 \mathrm{z}_{\mathrm{i}}=50.14973$ \\
\hline
\end{tabular}

As an illustration, after generating random deviates $\mathrm{z}_{\mathrm{i}}$ from lognormal distribution,10-year synthetically generated maximum annual runoff of Adada river is computed in Table-6. This procedure is repeated for Rivers Ajali, Ivo, Otamiri and Imo (Umuokpara) using the best fitting distribution of the random deviate and assuming that the maximum annual discharge in the year preceding the first discharge record is $\mathrm{Q}_{1}=0$

\section{Model Validation}

The scatter plot between the predicted runoff of the corresponding years for Rivers Adada, Ajali, Ivo, Otamiri and Imo (Umuokpara) and the observed 10year runoff is shown in Fig-2. The validity of the annual Markov models was verified using the values obtained for the coefficient of determination $\left(\mathrm{R}^{2}\right)$ of the scatter plot.

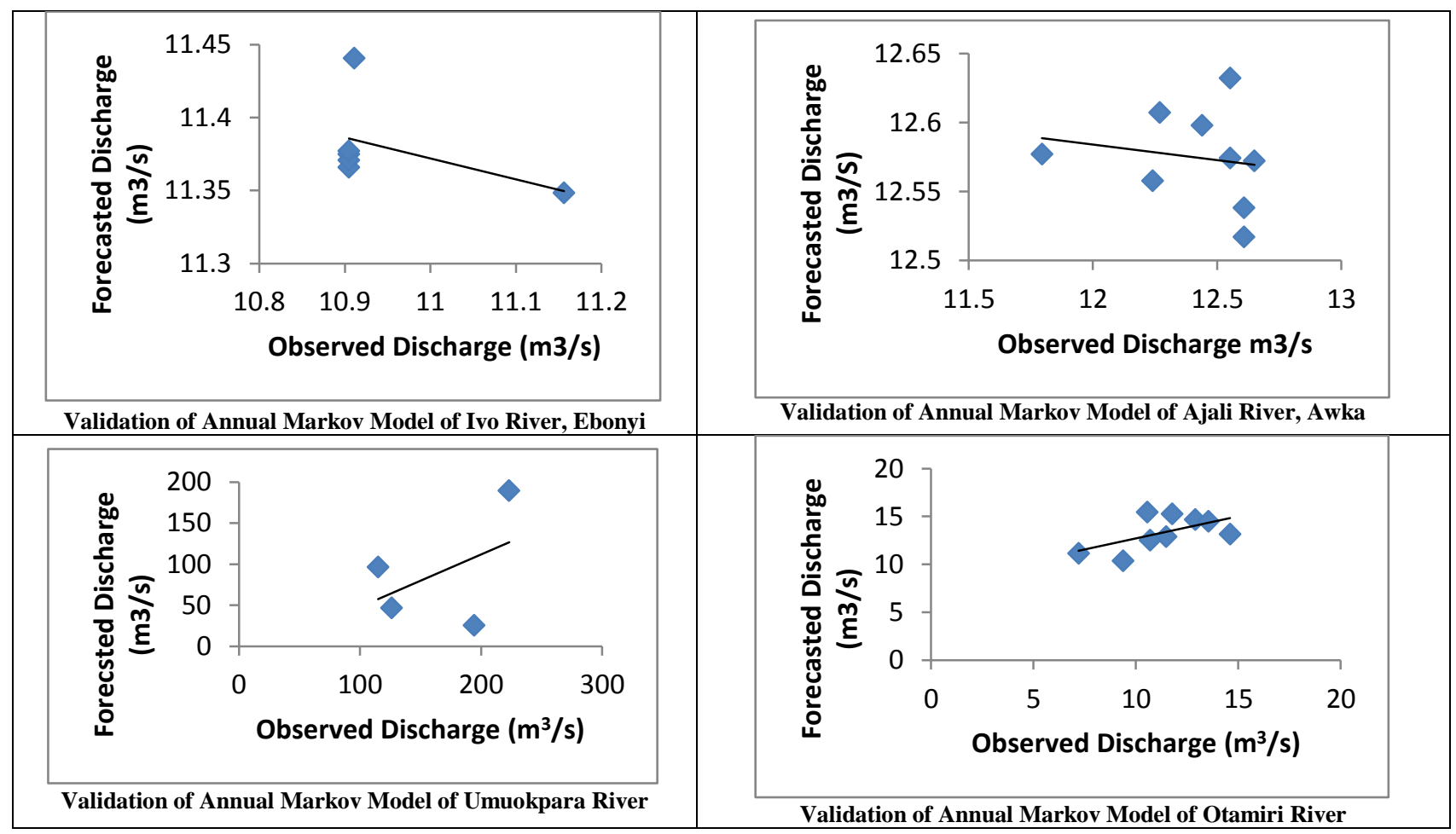




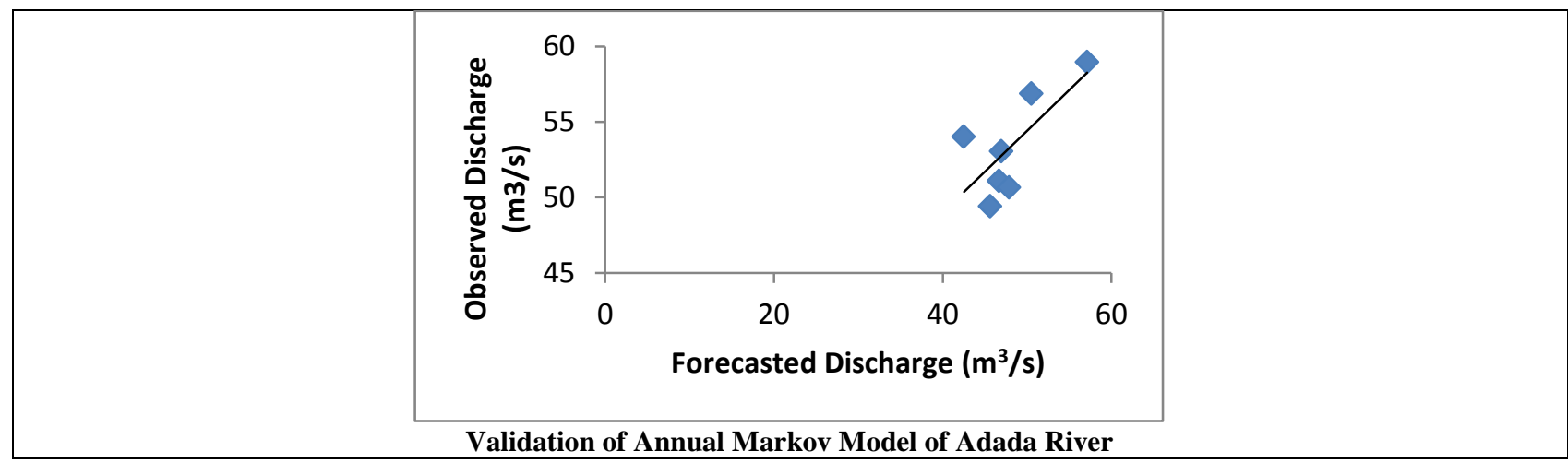

Fig-2: Validation of Annual Markov Model of Rivers in Southeast Nigeria

It can be observed that the scatter plots confirmed the values of the coefficients of determination for the Markov models in which Rivers Adada, Ajali, Ivo, Otamiri and Imo had values of $51.69 \%, 31.3 \%, 21.4 \%, 33 \%$ and $21 \%$ respectively (Fig-2). This implied that Markov model of River Adada would predict annual runoff better than those of the other rivers simply because the data of maximum annual runoff of River Adada fulfilled the major core assumption of the Markov model which is based on the fact that the whole impact the previous flow had on the current one is reflected in the value of the previous one.

\section{CONCLUSION}

The annual Markov models were fitted to the maximum annual runoffs of the selected catchment areas. The random deviates associated with Rivers Adada, Ajali, Ivo, Otamiri and Imo (Umuokpara) had lognormal $(\mathrm{p}=0.385)$, Weibull $(\mathrm{p}=0.205)$, Weibull $(\mathrm{p}$ $=0.010)$, normal $(p=0.910)$ and lognormal $(p=0.486)$. Markov model of River Adada has the highest coefficient of determination of $51.69 \%$ and is the best to predict annual runoff among other rivers simply because the whole impact the previous flow had on the current one is reflected in the value of the previous one.

\section{REFERENCES}

1. De Fraiture, C., Giordano, M., \& Liao, Y. (2008). Biofuels and implications for agricultural water use: blue impacts of green energy. Water Policy, 10: 67-81.

2. Wang, Y., Zheng, T., Zhao, Y., Jiang, J., Wang, Y., Guo, L., \& Wang, P. (2013). Monthly water quality forecasting and uncertainty assessment via bootstrapped wavelet neural networks under missing data for Harbin, China. Environ Sci Pollut Res, 20: 8909-8923.

3. Cui, Q.,Wang, X., Li, C., Cai, Y., \& Liang, P. (2016). Improved Thomas-Fiering and wavelet neural network models for cumulative errors reduction in reservoir inflow forecast. $J$ Hydroenviron Res, 13: 134-143.

4. Langat, P. K., Kumar, L., \& Koech, R. (2019). Identification of the Most Suitable Probability Distribution Models for Maximum, Minimum, and Mean Streamflow. Water. 11(4): 734.
5. Srikanthan, R., Amirthanathan, G., \& Kuczera. (2007). Real-time flood forecasting using ensemble Kalman filter. In: Proccedings of the MODSIM 2007 International Congress on Modelling and Simulation. ( Modelling and Simulation Society of Australia and New Zealand), 1789-1795.

6. Bolaji, G., Agbede, O., Adewumi, J., \& Akinyemi, J. (2008). Selection of flood frequency model in Niger basin using maximum likelihood method, edited by Adewumi, J., \& Akinyemi, J. (Water and Urban Development Paradigms: Towards an Integration of Engineering, Design and Management Approaches, Taylor \& Francis), 337.

7. Stedinger, J. R., Taylor, M. R. (1982). Synthetic streamflow generation, 1. Model verification and validation. Water Resour Res, 18(4): 909-918.

8. Wijayaratne, L. H., \& Chan, P. C. (1987). Synthetic Flow Generation with Stochastic Models, edited by Singh, V. P. (Flood Hydrology, Springer), 175-185.

9. Jothiprakash, V., \& Magar, R. B. (2012). Multitime-step ahead daily and hourly intermittent reservoir inflow prediction by artificial intelligent techniques using lumped and distributed data. $J$ Hydrol, 450: 293-307.

10. Yevjevich, V. (1972). Probability and Statistics in Hydrology. 1st Ed. (Water Resource Publications) 34-56.

11. Yapo, P., Sorooshian, S., \& Gupta, V. (1993). A Markov chain flow model for flood forecasting. Water Resource Res, 29(7): 2427-2436.

12. Zielinski, P. A. (1991). On meaning of randomness in stochastic environmental models. Water Resour Res, 29(7): 1607-161 1.

13. Karlsson, M., \& Yakowitz, S. T. (1987). Nearestneighbour methods for nonparametric rainfallrunoff forecasting. Water Resources Res, 23(7):1300-1308.

14. Smith, J. A. (1991). Long-range streamflow forecasting using nonparametric regression. Water Resources Bulletin, 27(1): 39-46.

15. Jackson, B. B. (1975). Markov mixture models for drought lengths. Water Resour Res, 11(1):64-74. 
16. Jackson, B. B. (1975). Birth-death models for differential persistence. Water Resour Res, vol. 11(1):75-95.

17. Haan, C. T., \& Allen, D. M. (1976). A Markov model of daily rainfall. Water Resour Res, 12(3):443-449.

18. Yakowitz S. T. (1979). A nonparametric model for daily river flow. Water Resour Res, 15(5):10351043.
19. Katz, R. W. (1981). On some criteria for estimating the order of a Markov chain. Technometrics, 23(3):243-249.

20. Yakowitz S. T. (1985). Markov flow models and the flood warning problem. Water Resour Res, 21(5):81-88.

21. Ofomata, G. E. K. (2001). Soil Erosion in Enugu Area of Nigeria. Nigerian Geographical Journal, 8:45-49. 